\title{
Incidence of psychotic disorders among first-generation immigrants and refugees in Ontario
}

\author{
Kelly K. Anderson PhD, Joyce Cheng MSc, Ezra Susser MD DrPH, Kwame J. McKenzie MD, \\ Paul Kurdyak MD PhD
}

$C M A J$ Podcasts: author interview at soundcloud.com/cmajpodcasts/psychotic-disorders

See also www.cmaj.ca/lookup/doi/10.1503/cmaj.150494

\begin{abstract}
Background: Evidence suggests that migrant groups have an increased risk of psychotic disorders and that the level of risk varies by country of origin and host country. Canadian evidence is lacking on the incidence of psychotic disorders among migrants. We sought to examine the incidence of schizophrenia and schizoaffective disorders in first-generation immigrants and refugees in the province of Ontario, relative to the general population.
\end{abstract}

Methods: We constructed a retrospective cohort that included people aged $14-40$ years residing in Ontario as of Apr. 1, 1999. Population-based administrative data from physician billings and hospital admissions were linked to data from Citizenship and Immigration Canada. We used Poisson regression models to calculate age- and sex-adjusted incidence rate ratios (IRRs) and 95\% confidence intervals ( $\mathrm{Cls}$ ) for immigrant and refugee groups over a 10-year period.
Results: In our cohort ( $n=4284$ 694), we found higher rates of psychotic disorders among immigrants from the Caribbean and Bermuda (IRR 1.60,95\% Cl 1.29-1.98). Lower rates were found among immigrants from northern Europe (IRR 0.50, 95\% Cl 0.28-0.91), southern Europe (IRR 0.60, 95\% Cl 0.41-0.90) and East Asia (IRR 0.56, 95\% Cl 0.41-0.78). Refugee status was an independent predictor of risk among all migrants (IRR 1.27, 95\% Cl 1.04-1.56), and higher rates were found specifically for refugees from East Africa (IRR 1.95, 95\% Cl 1.44-2.65) and South Asia (IRR $1.51,95 \% \mathrm{Cl} 1.08-2.12)$.

Interpretation: The differential pattern of risk across ethnic subgroups in Ontario suggests that psychosocial and cultural factors associated with migration may contribute to the risk of psychotic disorders. Some groups may be more at risk, whereas others are protected.
$\mathrm{M}$ eta-analytic reviews suggest that international migrants have a two- to threefold increased risk of psychosis compared with the host population, and the level of risk varies by country of origin and host country. ${ }^{1,2}$ This increased risk may persist into the second and third generations. ${ }^{2,3}$ Incidence rates are not typically found to be elevated in the country of origin: ${ }^{4-7}$ therefore, it is believed that the migratory or postmigration experience may play a role in the etiology.

The migration-related emergence of psychotic disorders is a potential concern in Canada, which receives about 250000 new immigrants and refugees each year. ${ }^{8}$ However, there is a notable lack of current epidemiological information on the incidence of psychosis among these groups. ${ }^{9}$ Hospital admission data from the early 1900s suggest that European migrants to British Columbia had a higher incidence of schizophre- nia than the general population,,$^{10}$ and more recent data from Ontario suggest higher rates of hospital admission for psychotic disorders in areas with a large proportion of first-generation migrants. ${ }^{11}$ The fact that a large and increasing proportion of Canada's population are migrants has been cited as a potential explanation for the higher prevalence of schizophrenia compared with international estimates. ${ }^{12}$

The province of Ontario is home to the largest number of migrants in Canada, with firstgeneration migrants constituting nearly $30 \%$ of the population. Canada operates on a human capital model of immigration, using a pointsbased system that favours younger age, higher education, and proficiency in English or French. Nearly $60 \%$ of all newcomers to Canada are economic migrants, $27 \%$ are sponsored by a relative living in Canada, and $13 \%$ are refugees or temporary workers. ${ }^{8}$ Canada also requires a prearrival
Competing interests: None declared.

This article has been peer reviewed.

Correspondence to: Kelly Anderson, kelly. anderson@schulich.uwo.ca

Accepted: Apr. 10, 2015 Online: May 11, 2015

CMAJ 2015. DOI:10.1503 /cmaj.141420 
medical examination, but less than $0.001 \%$ of all applications are denied on the basis of medical grounds, and exemptions may be granted for refugees and some family-reunification applicants. ${ }^{13}$

The Canadian migration process differs from that of many countries where the association between migration and psychotic disorders has been previously investigated. ${ }^{1,2}$ In most of these countries, migrants generally originate from a smaller number of countries that have historic ties to the host country, and there tends to be a low proportion of refugees, although these processes have changed in recent years. In Canada, migrants come from a wide array of countries, admission policies focus on migrants with professional skills and there is a larger proportion of refugees. Few studies to date have examined the role of refugee status in the risk of psychotic disorders $^{14}$ or have assessed all of the migrant groups within a country, because most studies focus on particular groups considered to be at high risk. ${ }^{1}$ An examination of migrants to Canada offers a unique opportunity to investigate the risk of psychotic disorders in a group with diverse geographical origins, and the larger proportion of refugees also allows us to investigate their risk separately from immigrant groups. Thus, the breadth, scope and scale of migration to Canada over time offers a diverse and deep population for advancing our understanding of why some groups may have a higher risk of psychotic disorders.

Our primary objective was to examine the incidence of schizophrenia and schizoaffective disorders over a 10-year period in first-generation immigrants and refugees in Ontario, relative to the general population. We also compared the incidence among specific migrant groups, stratified by country of birth and refugee status, because research suggests differences in the degree and direction of risk. ${ }^{1,2}$ We restricted the sample to first-generation migrants to estimate the extent to which sociodemographic factors had an impact on the risk of schizophrenia and schizoaffective disorders among all migrants.

\section{Methods}

\section{Study design}

We used a retrospective cohort design to estimate the incidence of schizophrenia and schizoaffective disorders among immigrants and refugees in Ontario, relative to the general population. The cohort included Ontario residents aged 14-40 years as of Apr. 1, 1999. This allowed for an age of onset up to 50 years over the 10-year follow-up period, which is the maxi- mum age used by some early intervention programs for psychosis in Ontario. Participants had to be eligible for the Ontario Health Insurance Plan (OHIP) in the 5 years before cohort inception, and anyone with a history of contact with services in Ontario for schizophrenia or schizoaffective disorder was removed as a prevalent case. The exclusion period for prevalent cases was up to 20 years, depending on the database used and the age of each participant.

\section{Data sources}

We obtained access to the data holdings of the Institute for Clinical Evaluative Sciences (ICES), which links patient records from multiple Ontario health administrative databases. The databases contain information on all medically necessary hospital and physician services funded under OHIP, which covers nearly the entire population of Ontario, including Canadian citizens, permanent residents, landed immigrants and refugees. We also linked data from Citizenship and Immigration Canada (CIC), which has a comprehensive database of all immigrants and refugees to Ontario dating back to 1985 . To link the CIC data to the ICES data holdings, a unique coded identifier was assigned using a combination of deterministic $(66.6 \%)$ and probabilistic $(19.1 \%)$ linkage, for a total linkage rate of $86.1 \%$. There was minimal missing data $(<1 \%)$ for the variables of interest in the current analysis.

Approval to access the data was obtained from the research ethics boards at the Centre for Addiction and Mental Health and the Sunnybrook Health Sciences Centre. The deidentified datasets were analyzed on site at ICES.

\section{Case ascertainment}

We used a 10-year window for case accrual (19992008, inclusive). One of the following criteria had to be met for classification as an incident case:

- a primary discharge diagnosis of schizophrenia or schizoaffective disorder from a general hospital bed (International Classification of Diseases, 9th Revision [ICD-9] code 295.x; International Statistical Classification of Diseases and Related Health Problems, 10th revision codes [ICD-10] code F20 or F25); or

- a Diagnostic and Statistical Manual of Mental Disorders, 4th ed., [DSM-IV] Axis 1 diagnosis of schizophrenia or schizoaffective disorder from a psychiatric hospital bed (DSM-IV code 295.x); or

- at least 2 OHIP billing claims or emergency department visits with a diagnostic code for schizophrenia or schizoaffective disorder (ICD-9 code 295.x; ICD-10 code F20 or F25) in a 12 -month period. 
This algorithm has been validated through comparison of the administrative coding in the ICES data holdings against medical chart diagnoses and was found to have high sensitivity $(91.6 \%)$, moderate specificity $(61.3 \%)$, a moderate positive predictive value $(67.4 \%)$ and a high negative predictive value $(89.3 \%)$ for a diagnosis of schizophrenia or schizoaffective disorder. ${ }^{15}$

We calculated person-time of follow-up from the time of cohort inception, with censoring at the index episode of psychotic disorder, death or the end of the follow-up period. Available sociodemographic data included age, sex, and urban versus rural place of residence. We also had data available on area-level income quintile, assigned based on the census dissemination area of each person's residential postal code. All variables were defined at the time of cohort entry.

\section{Exposure classification}

The exposure of interest was first-generation immigrant or refugee status, which includes people with a personal history of migration such that they were born outside of Canada. We linked the cohort with the CIC database and classified all people who were in the CIC database as "migrants" and those not in the database as "general population." Analyses are presented separately for immigrants and refugees.

We were unable to identify people who migrated before 1985 or those who were secondgeneration migrants, which refers to people who were born in Canada but have 1 or more parents who were born outside of Canada. Given that these people may also have an elevated risk of having a psychotic disorder, ${ }^{1,2}$ our "general population" comparison group is highly heterogeneous, both in terms of ethnicity and immigration status.

For all migrants, we calculated the age at migration and the length of time in Canada at the time of cohort entry. We also obtained information on country of birth, which was classified according to the groupings used by Statistics Canada. ${ }^{16}$

\section{Statistical analysis}

We summarized the demographic data for immigrants, refugees and the general population by calculating descriptive statistics, specifically proportions for categorical data, and means and standard deviations (SDs) for continuous data. We estimated the incidence rate of psychotic disorders for each group by directly standardizing to the 1991 Canadian population using the $\gamma$ distribution to adjust the estimates for age and sex. ${ }^{17}$

We used multivariate Poisson regression models to estimate the incidence rate ratios (IRRs) and 95\% confidence intervals (CIs) for each migrant subgroup, relative to the general population, adjusting for age and sex. We included a scaled deviance parameter in the models to account for observed overdispersion. We also used a multivariate Poisson regression model with scaled deviance to estimate the independent effects of sex, age at migration, length of time in Canada, urban residence, refugee status and income quintile. This portion of the analysis included only the migrant group.

All analyses were conducted using PROC GENMOD in SAS version 9.2. All results are presented as adjusted incidence rates and IRRs with corresponding 95\% CIs. Confidence intervals that do not overlap with unity are considered statistically significant.

\section{Results}

Our cohort included 4284694 people, of which 9.8\% ( $n=418433)$ were first-generation migrants. Of the migrant group, $22.7 \%(n=95148)$ had refugee status (Table 1). Less than $1 \%$ of the cohort $(n=38$ 539) died during the follow-up period. The incidence rate of psychotic disorders among the general population in our cohort was 55.6 (95\% CI 54.9-56.4) per 100000 personyears. The rate was similar among immigrants at 51.7 (95\% CI 49.2-54.4) per 100000 person-years and higher among refugees at 72.8 (95\% CI 67.178.9) per 100000 person-years. However, the IRR was not significant for either group (Table 2).

We found that the degree and direction of risk varied by refugee status and the country of birth (Table 2). Immigrants from the Caribbean and Bermuda had a higher risk of having a psychotic disorder compared with the general population (IRR $1.60,95 \%$ CI 1.29-1.98), whereas immigrants from northern Europe (IRR 0.50, 95\% CI 0.28 0.91), southern Europe (IRR 0.60, 95\% CI 0.410.90) and East Asia (IRR 0.56, 95\% CI 0.41-0.78) had lower risks. In the refugee group, people from both East Africa (IRR 1.95, 95\% CI 1.44-2.65) and South Asia (IRR 1.51, 95\% CI 1.08-2.12) had a significantly higher risk of having a psychotic disorder than the general population (Table 2).

Refugee status was an independent predictor of an increased risk of a psychotic disorder (IRR $1.27,95 \%$ CI 1.04-1.56) among all migrants (Table 3). There was a linear relation between income quintile and risk, with migrants living in the highest income areas having the lowest risk (IRR 0.52, 95\% CI 0.39-0.69).

\section{Interpretation}

In this study, we found higher rates of psychotic disorders among some migrant groups in Ontario, whereas other groups were protected. The differ- 
ential rates cannot be explained by variations in the country of origin, ${ }^{4-7}$ and the selective migration of people who have an increased risk is increasingly being refuted as a plausible explanation. ${ }^{18}$ The pattern we observed in Ontario suggests that psychosocial factors associated with the migratory experience and integration into Canada may contribute to the risk of psychotic disorders.

\section{Role of refugee status}

In our study, refugees had a higher risk of having a psychotic disorder than both nonrefugee migrants and the general population. This is consistent with Canadian findings for other mental health conditions, ${ }^{9}$ and further investigation of refugee groups in several key areas could further our understanding of the underlying etiology behind the association between migration and psychotic disorders.

First, refugees are likely to differ from other immigrants on the basis of educational and economic status, linguistic capacity, migration experiences, and exposure to adversity and trauma in the country of origin. ${ }^{13}$ There is some suggestion that experiences of adverse and stressful life events, either during childhood or adulthood, are associated with a three- to fourfold increased risk of schizophrenia. ${ }^{19-21}$
Second, refugee groups within Canada also face substantial adversity, such as housing instability, economic hardships, difficulties accessing health care, and a lack of educational and employment opportunities. ${ }^{22}$ Findings from a large metaanalysis suggest that postmigration conditions moderate mental health outcomes among refugees, and factors such as access to private accommodation and economic opportunities for refugees may help to mitigate the effects of premigration stressors. ${ }^{23}$ Indeed, our own findings suggest that neighbourhood-level income may be a protective factor against the risk of psychotic disorders.

Third, Canada's refugee protection program has 2 main streams: the Refugee and Humanitarian Resettlement Program, which includes refugees sponsored by the government and by private groups, and the In-Canada Asylum Program, which includes people who were granted refugee status after arriving in Canada in need of protection and filing a refugee claim. ${ }^{24}$ Our refugee group combined both streams of refugees, and did not include refugee claimants or those waiting for determination in Canada. A more in-depth investigation of the different refugee groups may provide additional insights into the underlying etiology.

Finally, recent Canadian evidence highlights the difficulties in distinguishing psychotic disor-

Table 1: Sociodemographic characteristics of 4284694 people aged 14-40 years living in Ontario as of Apr. 1, 1999

\begin{tabular}{|c|c|c|c|c|c|c|}
\hline \multirow[b]{2}{*}{ Characteristic } & \multicolumn{6}{|c|}{ Group; mean \pm SD and no. (\%) } \\
\hline & \multicolumn{2}{|c|}{$\begin{array}{c}\text { General population } \\
n=3866261\end{array}$} & \multicolumn{2}{|c|}{$\begin{array}{l}\text { Immigrants } \\
n=323285\end{array}$} & \multicolumn{2}{|c|}{$\begin{array}{l}\text { Refugees } \\
n=95148\end{array}$} \\
\hline Age at cohort entry, yr & \multicolumn{2}{|c|}{$27.9 \pm 7.9$} & \multicolumn{2}{|c|}{$29.0 \pm 7.7$} & \multicolumn{2}{|c|}{$29.7 \pm 7.7$} \\
\hline $\begin{array}{l}\text { Age at index diagnosis of } \\
\text { psychotic disorder, yr }\end{array}$ & \multicolumn{2}{|c|}{$32.1 \pm 8.6$} & \multicolumn{2}{|c|}{$31.5 \pm 8.4$} & \multicolumn{2}{|c|}{$32.7 \pm 8.5$} \\
\hline Age at immigration, yr & \multicolumn{2}{|c|}{-} & \multicolumn{2}{|c|}{$21.2 \pm 8.1$} & \multicolumn{2}{|c|}{$22.0 \pm 8.2$} \\
\hline Time in Canada, yr & \multicolumn{2}{|c|}{-} & \multicolumn{2}{|c|}{$8.1 \pm 2.6$} & \multicolumn{2}{|c|}{$7.9 \pm 2.7$} \\
\hline \multicolumn{7}{|l|}{ Sex } \\
\hline Female & 1922070 & $(49.7)$ & 166344 & $(51.5)$ & 38115 & $(40.1)$ \\
\hline Male & 1944191 & $(50.3)$ & 156941 & $(48.5)$ & 57033 & $(59.9)$ \\
\hline \multicolumn{7}{|l|}{ Residence } \\
\hline Rural & 543418 & $(14.1)$ & 4930 & $(1.5)$ & 332 & $(0.3)$ \\
\hline Urban & 3322843 & (85.9) & 318355 & $(98.5)$ & 94816 & $(99.7)$ \\
\hline \multicolumn{7}{|l|}{ Income quintile } \\
\hline 1 (lowest) & 722626 & $(18.7)$ & 106274 & (32.9) & 47466 & (49.9) \\
\hline 2 & 787781 & $(20.4)$ & 78050 & $(24.1)$ & 22078 & $(23.2)$ \\
\hline 3 & 796399 & $(20.6)$ & 59138 & (18.3) & 13058 & (13.7) \\
\hline 4 & 778377 & $(20.1)$ & 44485 & $(13.8)$ & 7892 & $(8.3)$ \\
\hline 5 (highest) & 767143 & (19.8) & 35276 & (10.9) & 4653 & $(4.9)$ \\
\hline Missing data & 13935 & $(0.4)$ & 62 & $(0.02)$ & 1 & $(0.001)$ \\
\hline
\end{tabular}


ders from other mental health diagnoses in immigrant and refugee groups, with posttraumatic stress disorder and adjustment disorder frequently misdiagnosed as a psychotic disorder, especially among people who arrived in Canada more recently. ${ }^{25}$ This diagnostic bias may explain the higher rates of psychotic disorders that we observed in refugee groups and warrants further investigation.

\section{Role of visible minority status}

We found higher rates of schizophrenia among immigrants from the Caribbean and Bermuda, as well as among refugees from East Africa and South Asia, which is consistent with the international literature. ${ }^{1,2}$ This shared risk across these diverse migrant groups is suggestive of a common underlying exposure. The literature suggests that the experience of discrimination may be one potential mechanism.

Experiences of interpersonal racism, as well as the perception of societal racism, have both been shown to have an independent effect on the likelihood of a psychotic disorder. ${ }^{26}$ The incidence of schizophrenia also varies across ethnic minority groups based on the degree of perceived discrimination of each group. ${ }^{27}$ Perceived discrimination has been found to be associated with more severe positive symptoms, as well as more severe symptoms of depression and anxiety, among migrants with a psychotic disorder. ${ }^{28}$ Similarly, experiences of discrimination have been found to be associated with psychotic experiences, ${ }^{29}$ delusional ideation ${ }^{30}$ and attenuated positive psychotic symptoms. ${ }^{31}$ Canadian research suggests that experiences of discrimination contribute to declines in mental health status among migrants, ${ }^{32}$ although data are lacking on their contribution to psychosis specifically.

Racism and discrimination are unlikely to solely explain the differences we observed between migrant groups. In the current study, a number of groups who may experience discrimi-

Table 2: Age- and sex-standardized incidence rates and rate ratios for psychotic disorders by migrant grouping, compared with the general population of Ontario

\begin{tabular}{|c|c|c|c|c|c|}
\hline Group & No. & $\%$ refugee & $\begin{array}{l}\text { Incidence rate } \\
\text { per } 100000 \\
\text { person-years }\end{array}$ & Immigrants & Refugees \\
\hline Immigrants & 323285 & - & 51.7 & $0.91(0.71-1.16)$ & - \\
\hline Refugees & 95148 & - & 72.8 & - & $1.24 \quad(0.86-1.81)$ \\
\hline North America & 8540 & 2.7 & 27.4 & $0.54(0.23-1.22)$ & $1.29(0.10-16.48)$ \\
\hline Central America & 17533 & 58.3 & 43.4 & $0.64(0.29-1.39)$ & $0.87(0.52-1.43)$ \\
\hline Caribbean and Bermuda & 41154 & 0.7 & 94.4 & $1.60(1.29-1.98)$ & $0.61(0.02-22.24)$ \\
\hline South America & 26886 & 7.4 & 62.2 & $1.06(0.76-1.48)$ & $1.15(0.42-3.12)$ \\
\hline Western Europe & 5646 & 1.8 & 24.8 & $0.41(0.13-1.27)$ & - \\
\hline Southern Europe & 31416 & 4.5 & 36.9 & $0.60(0.41-0.90)$ & $1.53(0.54-4.32)$ \\
\hline West Africa & 5348 & 29.7 & 96.1 & $1.66(0.84-3.28)$ & $1.07(0.32-3.57)$ \\
\hline East Africa & 21117 & 63.2 & 98.0 & $1.20(0.69-2.10)$ & $1.95(1.44-2.65)$ \\
\hline North Africa & 3934 & 23.9 & 60.4 & $0.61(0.17-2.12)$ & $2.22(0.79-6.30)$ \\
\hline Central Africa & 676 & 39.5 & 16.0 & $0.47(0.01-24.27)$ & - \\
\hline South Africa & 2776 & 4.2 & 41.7 & $0.66(0.19-2.31)$ & $3.01(0.24-38.5)$ \\
\hline $\begin{array}{l}\text { West central Asia and } \\
\text { Middle East }\end{array}$ & 35282 & 42.9 & 57.2 & $0.75(0.49-1.15)$ & $1.28(0.91-1.80)$ \\
\hline East Asia & 50294 & 2.5 & 32.8 & $0.56(0.41-0.78)$ & $0.72(0.14-3.59)$ \\
\hline
\end{tabular}


nation in Canada, such as groups from East Asia, did not have a higher risk of having a psychotic disorder. This reflects that there are likely multiple social determinants involved in the development of psychosis.

\section{Role of socioeconomic position}

Although the higher risk of psychotic disorders among some migrant groups is well established, $, 1,2$ relatively fewer studies have reported that some migrant groups may be protected compared with the host population. In the current study, we found that immigrants from northern and southern Europe and from East Asia had lower rates of psychotic disorders. It is possible that these groups are more established and better positioned socioeconomically relative to other migrant populations in Ontario.

Prior research suggests that the relative position of specific migrant groups within the host

Table 3: Factors associated with psychotic disorders among migrants in Ontario $(n=418433)$

\begin{tabular}{|c|c|c|}
\hline Variable & \multicolumn{2}{|c|}{$\mathrm{IRR}^{*}(95 \% \mathrm{Cl})$} \\
\hline \multicolumn{3}{|l|}{ Sex } \\
\hline Female & & Ref \\
\hline Male & 1.45 & $(1.33-1.58)$ \\
\hline \multicolumn{3}{|c|}{ Age at immigration, yr } \\
\hline $0-4$ & & Ref \\
\hline $5-9$ & 1.37 & $(0.98-1.93)$ \\
\hline $10-14$ & 1.41 & $(0.99-2.00)$ \\
\hline 15-19 & 0.88 & $(0.61-1.26)$ \\
\hline $20-24$ & 0.82 & $(0.55-1.21)$ \\
\hline $25-29$ & 0.65 & $(0.42-1.02)$ \\
\hline $30-34$ & 0.63 & $(0.44-0.90)$ \\
\hline $35-39$ & 0.59 & $(0.35-0.99)$ \\
\hline \multicolumn{3}{|l|}{ Residence } \\
\hline Rural & & Ref \\
\hline Urban & 1.37 & $(0.82-2.29)$ \\
\hline \multicolumn{3}{|l|}{ Refugee status } \\
\hline Nonrefugee & & Ref \\
\hline Refugee & 1.27 & $(1.04-1.56)$ \\
\hline \multicolumn{3}{|c|}{ Income quintile } \\
\hline 1 (lowest) & & Ref \\
\hline 2 & 0.87 & $(0.76-1.00)$ \\
\hline 3 & 0.78 & $(0.64-0.95)$ \\
\hline 4 & 0.68 & $(0.53-0.86)$ \\
\hline 5 (highest) & 0.52 & $(0.39-0.69)$ \\
\hline \multicolumn{3}{|c|}{$\begin{array}{l}\text { Note: } \mathrm{Cl}=\text { confidence interval, IRR = incidence rate ratio. } \\
\text { *Poisson model adjusted for sex, age at immigration, } \\
\text { length of time in Canada, residence, refugee status and } \\
\text { income quintile. }\end{array}$} \\
\hline
\end{tabular}

country may be important in understanding the etiology behind the association between migration and psychotic disorders. Research from Israel has found that second-generation migrants did not have a higher risk of schizophrenia compared with the host population, ${ }^{33}$ which is in contrast to second-generation migrants in many countries. ${ }^{1,2}$ However, the immigration period considered in the Israeli study brought many Jewish refugees from Europe after World War II, and people who had been minorities in their country of origin were now part of the ethnic and religious majority.$^{33}$ Similarly, minority groups who are relatively advantaged with respect to socioeconomic factors have also been found to have similar rates of psychotic disorders as the majority population, ${ }^{34}$ most notably migrants from Western countries to the Netherlands. ${ }^{35,36}$ Indeed, Canada's immigration policies, which favour economic migrants who are more educated and proficient in English or French, may help to explain our findings of a reduced rate of psychotic disorders among some migrant groups.

\section{Strengths and limitations}

Our findings are strengthened by the use of a large, population-based database and a focus on firstgeneration migrants. Most immigrants and refugees to Canada are covered by the universal health care system, which increases the accuracy and representativeness of the administrative data. Additionally, we used data from the CIC to estimate person-time denominators, rather than census data, because the latter has been criticized in other jurisdictions for underrepresenting ethnic minority groups and therefore inflating incidence estimates. ${ }^{14}$

Our findings should be interpreted in light of a number of limitations. About $15 \%$ of records in the CIC database could not be linked to the ICES data holdings, and it is unknown whether these migrants may differ systematically from those whose data were successfully linked. The CIC database also extends back to 1985 and only includes migrants who landed in Ontario; therefore, any people who migrated before this date or who originally landed in a different Canadian province will be included in the reference group. Indeed, the migrant group comprises $10 \%$ of our sample, whereas about $30 \%$ of Ontario's population is composed of first-generation migrants. ${ }^{37}$ Studies show that immigrants who have been in Canada for more than 10 years have worse health than newcomers. ${ }^{32}$ In addition, people who first arrived in different provinces will have had multiple migrations. Both of these groups would be included in the reference group.

We have also misclassified second-generation migrants, who comprise $22.5 \%$ of the population 
of Ontario, as part of the reference group. ${ }^{37}$ Research suggests that the risk of having a psychotic disorder in second-generation migrants is as high or higher than in the first generation, ${ }^{1,2}$ and second-generation migrants born to newly arrived migrant families may also face substantial stressors and hardships. If we assume that the risk is higher among both first- and secondgeneration migrants and those who have multiple migrations, then these exposure misclassifications would dilute the observed association between migration and the risk of psychotic disorders, and therefore the parameter estimates that we present are likely conservative. This may not be a valid assumption, however, given that we found lower rates of psychotic disorders in some migrant groups. If the low rates for these migrant groups decreased the overall rate of the reference population, then our IRRs would overestimate the difference between groups. However, the incidence rate that we report for the general population is higher than estimates from other jurisdictions ${ }^{38}$ although consistent with other Canadian estimates ${ }^{39,40}$ and with estimates obtained from studies using a longitudinal sampling frame ${ }^{41}$ as was done in the current analysis. This likely does not explain the differences in rates that we observed between groups.

Another limitation to the interpretation of our findings is that all covariates were defined at the time of cohort entry, and we did not account for time-varying exposures in our survival analyses. As such, we are unable to assess whether exposure to urban living or socioeconomically deprived living conditions changed throughout the risk period. We also cannot account for the cumulative effects of these exposures over time. This distinction could have important implications for understanding the underlying etiology behind the associations we observed.

We were limited by the availability of data in the administrative database and therefore were unable to account for other important confounding factors, such as the social and economic status of migrants and reasons for migration. We also did not conduct an in-depth analysis of the effect of age at migration, and prior research suggests that people who migrate very early in life have the highest risk of a subsequent psychotic disorder. ${ }^{42}$ Our findings suggest a similar trend, and we will explore this in greater detail in a future paper.

The diagnostic information available in the database are assigned for billing purposes and have not been standardized across various service providers or validated for different ethnic groups. The moderate positive predictive value $(67.4 \%)$ associated with the diagnostic algorithm that we used indicates that a proportion of cases in our sample may be false-positives, which may have also contributed to the high crude incidence rate we observed compared with other jurisdictions. ${ }^{38}$ Additionally, the diagnostic algorithm that we used was validated for chronic psychotic illness, ${ }^{15}$ and its performance may differ for firstonset or single acute episodes of psychotic disorders.

\section{Conclusion}

Our findings suggest that particular immigrant and refugee groups may have a higher risk of psychotic disorders. Migrant status, in particular refugee status, needs to be considered as an important risk factor for psychotic disorders in Ontario. Future research should explore potential protective factors in migrant groups who have a lower risk of psychotic disorders to inform the design of support programs for high-risk groups. Given that Canada is currently experiencing a rapid growth in the population of foreign-born citizens - one of the highest rates of any Western nation ${ }^{8}$ - the mental health status of immigrants and refugees should be a national priority.

\section{References}

1. Cantor-Graae E, Selten J. Schizophrenia and migration: a metaanalysis and review. Am J Psychiatry 2005;162:12-24.

2. Bourque F, van der Ven E, Malla A. A meta-analysis of the risk for psychotic disorders among first- and second-generation immigrants. Psychol Med 2011;41:897-910.

3. Amad A, Guardia D, Salleron J, et al. Increased prevalence of psychotic disorders among third-generation migrants: results from the French Mental Health in General Population survey. Schizophr Res 2013;147:193-5.

4. Mahy GE, Mallett R, Leff J, et al. First-contact incidence rate of schizophrenia on Barbados. Br J Psychiatry 1999;175:28-33.

5. Hanoeman M, Selten J-P, Kahn RS. Incidence of schizophrenia in Surinam. Schizophr Res 2002;54:219-21.

6. Hickling FW, Rodgers-Johnson P. The incidence of first contact schizophrenia in Jamaica. Br J Psychiatry 1995;167:193-6.

7. Bhugra D, Hilwig M, Hossein B, et al. First-contact incidence rates of schizophrenia in Trinidad and one-year follow-up. $\mathrm{Br} J$ Psychiatry 1996;169:587-92.

8. Chagnon J. Migration: International, 2010 and 2011. Report on the demographic situation in Canada. Ottawa: Statistics Canada; 2013. Cat. no. 91-209-X. Available: www.statcan.gc .ca/pub/91-209-x/2013001/article/11787-eng.pdf (accessed 2014 July 15).

9. Hansson EK, Tuck A, Lurie S, et al. Rates of mental illness and suicidality in immigrant, refugee, ethnocultural, and racialized groups in Canada: a review of the literature. Can J Psychiatry 2012;57:111-21.

10. Smith GN, Boydell J, Murray RM, et al. The incidence of schizophrenia in European immigrants to Canada. Schizophr Res 2006;87:205-11.

11. Durbin A, Lin E, Taylor L, et al. First-generation immigrants and hospital admission rates for psychosis and affective disorders: an ecological study in Ontario. Can J Psychiatry 2011;56: 418-26.

12. Dealberto M-J. Are the rates of schizophrenia unusually high in Canada? A comparison of Canadian and international data. Psychiatry Res 2013;209:259-65.

13. MacPherson D, Gushulak B. Migrants and the epidemiology of psychiatric disorders in Canada. In: Cairney J, Streiner DL, editors. Mental disorder in Canada: an epidemiological perspective. Toronto: University of Toronto Press; 2010:286-303.

14. McKenzie K, Fearon P, Hutchinson G. Migration, ethnicity, and psychosis. In: Morgan C, McKenzie K, Fearon P, editors. Society and psychosis. Cambridge: Cambridge University Press; 2008: $143-60$. 
15. Kurdyak P, Lin E, Green D, et al. Validation of a population-based algorithm to detect chronic psychotic illness. Can J Psychiatry. In press.

16. Appendix 1.5. Places of birth disseminated in the 2011 National Household Survey. In: National Household Survey dictionary. Ottawa: Statistics Canada; 2011:210-5. Cat. no. 99-000-X2011001.

17. Fay MP, Feuer EJ. Confidence intervals for directly standardized rates: a method based on the gamma distribution. Stat Med 1997; 16:791-801.

18. Bourque F, van der Ven E, Fusar-Poli P, et al. Immigration, social environment and onset of psychotic disorders. Curr Pharm Des 2012;18:518-26.

19. Matheson SL, Shepherd AM, Pinchbeck RM, et al. Childhood adversity in schizophrenia: a systematic meta-analysis. Psychol Med 2013;43:225-38.

20. Varese F, Smeets F, Drukker M, et al. Childhood adversities increase the risk of psychosis: a meta-analysis of patient-control, prospective- and cross-sectional cohort studies. Schizophr Bull 2012;38:661-71.

21. Beards S, Gayer-Anderson C, Borges S, et al. Life events and psychosis: a review and meta-analysis. Schizophr Bull 2013, 39:740-7.

22. Beiser $M$. The health of immigrants and refugees in Canada. Can J Public Health 2005;96(Suppl 2):S30-44.

23. Porter M, Haslam N. Predisplacement and postdisplacement of refugees and internally displaced persons. JAMA 2005;294:602-12.

24. The refugee system in Canada. Ottawa: Citizenship and Immigration Canada; 2015. Available: www.cic.gc.ca/english/ refugees/canada.asp (accessed 2015 Mar. 3).

25. Adeponle AB, Thombs BD, Groleau D, et al. Using the cultural formulation to resolve uncertainty in diagnoses of psychosis among ethnoculturally diverse patients. Psychiatr Serv 2012; 63:147-53.

26. Karlsen S, Nazroo JY, McKenzie K, et al. Racism, psychosis and common mental disorder among ethnic minority groups in England. Psychol Med 2005;35:1795-803.

27. Veling W, Selten J-P, Susser E, et al. Discrimination and the incidence of psychotic disorders among ethnic minorities in the Netherlands. Int J Epidemiol 2007;36:761-8.

28. Berg AO, Melle I, Rossberg JI, et al. Perceived discrimination is associated with severity of positive and depression/anxiety symptoms in immigrants with psychosis: a cross-sectional study. BMC Psychiatry 2011;11:77.

29. Oh H, Yang LH, Anglin DM, et al. Perceived discrimination and psychotic experiences across multiple ethnic groups in the United States. Schizophr Res 2014;157:259-65.

30. Janssen I, Hanssen M, Bak M, et al. Discrimination and delusional ideation. Br J Psychiatry 2003;182:71-6.

31. Anglin DM, Lighty Q, Greenspoon M, et al. Racial discrimination is associated with distressing subthreshold positive psychotic symptoms among US urban ethnic minority young adults. Soc Psychiatry Psychiatr Epidemiol 2014;49:1545-55.

32. De Maio FG, Kemp E. The deterioration of health status among immigrants to Canada. Glob Public Health 2010;5:462-78.

33. Corcoran C, Perrin M, Harlap S, et al. Incidence of schizophrenia among second-generation immigrants in the Jerusalem perinatal cohort. Schizophr Bull 2009;35:596-602.

34. Suvisaari J, Opler M, Lindbohm M, et al. Risk of schizophrenia and minority status: a comparison of the Swedish-speaking minority and the Finnish-speaking majority in Finland. Schizophr Res 2014;159:303-8.
35. Selten JP, Laan W, Kupka R, et al. Risk of psychiatric treatment for mood disorders and psychotic disorders among migrants and Dutch nationals in Utrecht, the Netherlands. Soc Psychiatry Psychiatr Epidemiol 2012;47:271-8.

36. Veling W, Selten J-P, Veen N, et al. Incidence of schizophrenia among ethnic minorities in the Netherlands: a four-year firstcontact study. Schizophr Res 2006;86:189-93.

37. 2011 National Household Survey: data tables. Ottawa: Statistics Canada; 2011. Available: www12.statcan.gc.ca/nhs-enm/2011/ dp-pd/dt-td/Index-eng.cfm (accessed 2014 Sept. 23).

38. McGrath J, Saha S, Chant D, et al. Schizophrenia: a concise overview of incidence, prevalence, and mortality. Epidemiol Rev 2008:30:67-76

39. Anderson KK, Fuhrer R, Abrahamowicz M, et al. The incidence of first-episode schizophrenia-spectrum psychosis in adolescents and young adults in Montreal: an estimate from an administrative claims database. Can J Psychiatry 2012;57:626-33.

40. Vanasse A, Courteau J, Fleury M-J, et al. Treatment prevalence and incidence of schizophrenia in Quebec using a population health services perspective: different algorithms, different estimates. Soc Psychiatry Psychiatr Epidemiol 2012;47:533-43.

41. Hogerzeil SJ, van Hemert M, Rosendaal FR, et al. Direct comparison of first-contact versus longitudinal register-based case finding in the same population: early evidence that the incidence of schizophrenia may be three times higher than commonly reported. Psychol Med 2014;44:3481-90.

42. Veling W, Hoek HW, Selten J-P, et al. Age at migration and future risk of psychotic disorders among immigrants in the Netherlands: a 7-year incidence study. Am J Psychiatry 2011;168:1278-85.

Affiliations: Departments of Epidemiology and Biostatistics, and Psychiatry (Anderson), Western University, London Ont.; Institute for Clinical Evaluative Sciences (Anderson, Cheng, Kurdyak), Toronto, Ont.; Centre for Addiction and Mental Health (Cheng, McKenzie, Kurdyak), Toronto, Ont.; Mailman School of Public Health (Susser), Columbia University, New York, NY; Department of Psychiatry (McKenzie, Kurdyak), University of Toronto, Toronto, Ont.

Contributors: All of the authors were involved in the conception and design of the study, the interpretation of data and the revision of the article for intellectual content. Kelly Anderson, Joyce Cheng and Paul Kurdyak analyzed the data. Kelly Anderson wrote the first and subsequent drafts of the article. All of the authors gave final approval of the version to be published and agreed to act as guarantors of the work.

Disclaimer: This study was funded in part by a Fellowship Award to Kelly Anderson from the Canadian Institutes of Health Research (no. 274885). This study was supported by the Institute for Clinical Evaluative Sciences (ICES), which is funded by an annual grant from the Ontario Ministry of Health and Long-term Care (MOHLTC). The immigration data was provided to ICES by Citizenship and Immigration Canada (CIC). The opinions, results and conclusions reported in this paper are those of the authors and are independent from the funding sources. No endorsement by ICES, the CIC or the MOHLTC is intended or should be inferred. 